\title{
New broom sweeps cleaner
}

\section{Moscow}

Mr Boris G. Saltykov, Minister of Science, University and Technology Policy in the new Russian government, is energetic, thoughtful and imaginative. But circumstances require that he must also be a realist. A balanced budget requires that the money-printing presses should be stopped and that there will be hard times for many people and institutions when that happens. One prospect is that jobs will be lost. Saltykov says he expects the number of people working for the academic sector, chiefly that of the Russian Academy of Sciences, to have declined by between 20 and 30 per cent by the end of 1993. "It is obligatory", he said in his ministry office last Friday.

The government, Saltykov said, does not have the money to support "the whole old structure of research". People repeatedly visit him asking for extra funds for particular projects, but "I have no additional money". Instead, "I have promised to help with getting help" from outside.

Saltykov's analysis of the present situation is simple: there is a struggle, he says, between different parts of society. "The simple people on the streets" have no particular wish to support science, "especially after Chernobyl". And, in a democracy, public opinion counts for something.

With some passion, the minister nevertheless insists that it is in the interests of "world science" that help should materialize. It is not just that, otherwise, many people from defence research will end up assisting with the proliferation of defence technology but that the world will be the poorer if Russian science goes to the wall.

Saltykov hopes for much from the foundation for assisting ex-Soviet science advocated by $M$. François Mitterrand, the President of France, among others, partly at the urging of Dr Carlo Rubbia, the director-general of the European highenergy physics laboratory (CERN) in Geneva. The hope is that decisions about the foundation, especially about its scope, will be reached during February.

Meanwhile, he seems to be doing what he can to put existing institutions on a clearer footing. Thus Russian membership of CERN will continue, thanks to a deal with Rubbia allowing the contribution of SFr600,000 to be postponed for a year: in return, Saltykov has agreed to continue to support the home bases, chiefly at Serpukhov and Dubna, of Russians collaborating on experiments at CERN, who may be as many as 20 at any one time. Even more generously, the nine Russians at DESY, the electron accelerator laboratory in Hamburg, will be maintained from German funds during the year ahead.

But high-energy physics in general does not have a bright future. The electron collider being built at Serpukhov (and already two years late) will not be completed unless the economic climate improves. There is, for the time being, no chance that the $40-\mathrm{km}$-long colliding machine, based on two opposed linear accelerators, will ever be built.

Dubna is a different case (see page 391). The objective here is to breathe "new life" into a laboratory too much concerned with high-energy physics and too little with general and applicable physics. Among other things, the minister has taken the unprecedented step of advertising for a new director on the open market.

Another reorganization that seems on paper already to be a success is that of the instrument technology institute at Leningrad, previously an awkward joint venture between the Academy of Sciences and a production ministry. The institute has now been founded as a joint-stock company, 40 per cent of which has been sold to IBM and Deutsche Bank. The institute's strong suit is the design of sophisticated instruments but, to cut its commercial teeth, it is talking with suppliers in the Far East about the manufacture of personal computers.

That project raises a complaint from Saltykov - about the committee called CoCom, based in Paris, with continuing responsibility for licensing the export of strategic materials to eastern Europe and to the ex-Soviet Union. He says he can understand why it came into being, but not why it continues to superintend such a wide range of devices - custom-built chips for instruments, for example. $\mathrm{He}$ suspects it is another example of people hanging on to obsolete jobs.

On the academic front, change will be harder to bring about. Acknowledging that the Soviet Academy had become "a kind of science ministry", Saltykov was implicitly acknowledging that his own existence has robbed the academy of part of its function. One gathers that the minister (who was an academy servant in charge of a science policy study before becoming a politician) will let the academy work out its own solutions (or salvation) within the confines of the budget.

Earlier last week, Academician Yu. Ossipov, the newly elected president of the Russian Academy, had said that his first task is to "preserve the academy", but even that does not imply no change. In reality, opinion within the academy is divided. Casual conversation uncovered two academicians holding that the academy should withdraw from much of the applied research for which it is now responsible and also form stronger bridges with the universities. (The second said he was the only academician to hold these radical views, but, told that there was at least one other, instantly identified the first informant, suggesting that his claim to uniqueness may be almost correct.)

On links between research and the universities, there seems general agreement that change must be slow. Saltykov says that Russia has inherited roughly 600 of the 900 institutions of university rank in the old Soviet Union, of which a few, "maybe 20 or 30 , are really excellent". The proportion, he says, is not very different from the proportion of research universities in the United States. He lists among the outstanding universities the Moscow State University, the Moscow Physical-Technical Institute (his own alma mater) and Leningrad University. Part of the obstacle to change is the fear among university teachers that they would be intellectually swamped if researchers also habitually taught. Saltykov would like to see some change, but perhaps only when other problems are less pressing.

The problem of defence research is one of these, and for good reasons. Defence research is estimated to employ 35 per cent of Russian scientists, and to have taken 80 per cent of research funding. It has traditionally been well paid, but now there is no point in turning out "new tanks just to destroy them". One step along the road to pacification has been to convert the Kurchatov Institute, a kind of Los Alamos in suburban Moscow, into a "national centre", but there is plainly a long way further to go.

So with everything in Russia, Saltykov repeatedly returned to the dominance of the economic problem, which he often called a "crisis". If that is not solved, no amount of toiling in the vineyards of a ministry will count for much. Saltykov knows that, but too many of his constituents are unpersuaded. John Maddox

ENVIRONMENT

\section{UK sets 'early warning system'}

London

NINE UK government agencies, led by the Natural Environment Research Council (NERC), are setting up a new 'early warning system' designed to detect environmental change. Starting with eight stations, the Environmental Change Network $(\mathrm{ECN})$ aims to monitor a range of British terrestrial ecosystems, recording a suite of data from simple meteorological measurements to samples of soil invertebrates. The network is expected to help to define future UK government environmental policy, but more stations may have to be added to distinguish between local environmental fluctuations and national trends. Relatively few countries have set up similar monitoring networks. The new British effort joins similar monitoring schemes in China, Sweden and the United States. P.A. 